\title{
EULAR Standing Committee for Education and Training
}

\section{Report Fune 2001}

The Standing Committee for Education and Training continues to work closely with the European Union of Medical Specialists (UEMS) and European Board of Rheumatology to achieve its goals.

When the committee was created eight years ago it agreed a mission statement and it has largely achieved these goals since then.

\section{Undergraduate education}

Guidelines for rheumatology undergraduate education have been developed and published. In most medical schools, rheumatology undergraduate education is concerned with musculoskeletal conditions, and a curriculum that covers all musculoskeletal conditions is being developed in collaboration with other relevant organisations, most importantly EFORT and UEMS Orthopaedic Committee. A draft document was produced after a workshop held in Lisbon, Portugal, 2001.

A workshop was also organised during ILAR in Edmonton, Canada, in August 2001, to achieve internationally agreed guidelines for musculoskeletal undergraduate education. This is part of the Bone and Joint Decade initiative.

Surveys have been undertaken of medical schools to monitor the provision of undergraduate musculoskeletal education.

\section{Primary care doctors}

The standing committee is assessing the regulations for training of primary care doctors in Europe and whether this includes adequate education in the range of musculoskeletal conditions.

\section{Specialist training}

Minimum standards have been developed for specialist training in collaboration with UEMS and the European Board of Rheumatology, and these continue to be reviewed. A database of training centres has been developed, which includes information as to whether they are prepared to take part in educational visits and an exchange training programme. A postgraduate course was organised during the week of EULAR 2000 and a further "Introduction to ultrasound" course has been held in Milan, Italy. A "Clinical skills" course has also been held in Copenhagen, Denmark.

Travel bursaries continue to be made available that facilitate visits by young rheumatologists to other training centres.

\section{Continuing medical education}

In collaboration with UEMS and the European Board of Rheumatology, a charter on CME in rheumatology and a core curriculum have been developed. Methods for assessment of CME and professional development continue to be formulated. Criteria for meetings and courses have been introduced.

\section{General}

Professor AD Woolf has completed his term as chairman of the standing committee. Professor José da Silva from Coimbra, Portugal, will be the next chairman of this committee.

Chairman,

EULAR Standing Committee on Education and Training,

Duke of Cornwall Rheuatology unit,

Royal Cornwall Hospital,

Truro TR1 3Lf, UK

\section{Health Professionals Standing Committee}

\section{Report to the General Assembly, 2001}

In line with the objectives presented on my appointment (in 1995) education programmes have continued annually: 1998 to Lithuania, 1999 to Czech Republic, 2000 to Poland.

This year to Hungary in the autumn, where the programme will include assessment, evidence based practice, patient education, and exercise tolerance. Workshops on splinting, hydrotherapy, collaborative care plans, and documentation will also be held.

The appointment in 1999 of an education coordinator, Ms Anne Bos, has produced numerous benefits, including devising courses to meet the individual needs of the host country.

In addition to the annual educational visits a proposal for individuals to undertake educational visits has been approved and supported by the executive committee. Such visits will have agreed objectives and learning contracts, the participants being invited to present their outcomes at the annual conference.

The standing committee has been active in producing the programme for the annual conference.
In 2000 the first newsletter was published by the editor, Ulla Nordenskiold. It was well received, but Ulla emphasises that the newsletter is only as good as its contributors. She looks forward to receiving content from anyone for the next issue.

All member countries without health professional representation in EULAR have been recently contacted to nominate a representative-I eagerly await their responses.

The Italian Health Professionals organisation is being reformed with the support of Professor Mattucci Cerinic. The standing committee looks forward to supporting them in their formation and future education programmes. With the support of Professor Brancho, we hope to facilitate the formation of a health professionals organisation in Portugal.

Topics for allied health professionals research are being sort, the funding having been agreed. It is hoped that proposals for multicountry/multicentre initiatives will be exciting and innovative.

In September 2000 Willy Peeters retired as the Belgian representative. Willy, along with Vicky Stephenson, was the 
originator and backbone of the EULAR Health Professionals. The sincere thanks of EULAR and the standing committee go to Willy for his support and contribution.

The first vice president of the health professionals, Jana Korandova, is retiring from her term of office. Jana has set very high standards. Her contribution as vice president will be missed, but I know she will join me in wishing her successor every success in this challenging role. Jana will continue as her country's representative, so her talents will not be lost to us.

Finally, a thank you to Fred and Ellie Wyss, to Eugenio Plozza, to Sophie Edwards for her support as personal assistant to the health professionals, and last, but by no means least, the standing committee for their total support of me as Chair.

Staffordshire, UK

N PRICE

\section{Report of the EULAR Standing Committee for International clinical Studies Including therapeutic Trials (ESCISIT)}

The committee has gone through a very active and productive period thanks to the contribution of all its members in the different working groups. As a result of this, the second volume of the EULAR Handbook of Clinical Assessments in Rheumatoid Arthritis has been published. The book can be ordered via the ESCISIT secretariat and is available in more than five different languages.

In addition to this, various new guidelines have been developed in the past year. Guidelines for the treatment of knee osteoarthritis (Ann Rheum Dis 2000;59:936-44) and for the assessment of disease activity in systemic sclerosis (Ann Rheum Dis 2001;60:585-98) have been published in the Annals of the Rheumatic Diseases. Guidelines for musculoskeletal ultrasound in rheumatology and a clinical guideline for referral of patients with early rheumatoid arthritis have just been finished. Several other working groups are active in different fields of rheumatology discussing treatment guidelines or developing new ways to assess and monitor these diseases. For several years a EULAR course in arthroscopy has been running.
As it became increasingly difficult for everyone to have an overview of all the continuing activities it was decided to start an ESCISIT newsletter, which would be published three times a year and distributed to all members of the committee as well as to the national societies. Those who are interested in being placed on the mailing list should contact the ESCISIT secretariat. The first issue was released in January 2001 and the second one just before the Prague meeting. The newsletter includes an overview of all committee activities and European clinical trials in rheumatoid arthritis. The next planned meeting of the committee will be during the EULAR congress in Stockholm, June 2001.

P L C M VAN RIEL

Chairman,

ESCISIT secretariat,

University Medical Centre Nijmegen,

546 Department of Rheumatology,

PO Box 9101,

6500 HB Nijmegen, The Netherlands

\section{Standing Committee on Investigative Rheumatology}

This standing committee generally meets twice a year: during the annual EULAR Congress and during the European Workshop for Rheumatology Research. During these meetings information is provided about the activities of the study groups and of the EULAR organisation. Last year the standing committee contributed again to the organisation of the EULAR-ACR exchange programme. Four academic rheumatologists were selected to visit research centres in the United States in November 2000. The European investigators were Drs Grahame, Pap, Guerne, and Kamashta. This year a similar number of American investigators will visit European research centres. Furthermore, several members of this standing committee participated in the scientific programme of the annual EULAR Congress as well as in committees that selected candidates for research prizes.

The reports of the study groups can be summarised as follows.

\section{Consensus study group on autoantibodies}

The group's annual exercise was run in the autumn of 2000. As with the previous year's exercise, this consisted of two parts: (a) 10 sera which had to be analysed for autoantibodies by the laboratories current techniques; $(b)$ 20 digital images of antinuclear antibody patterns which had to be identified.

Forty laboratories took part and, despite some problems with delivery, 38 laboratories returned at least part data.
Two new laboratories took part this year, and three further laboratories are on the waiting list.

The results of both exercises were reviewed at the meeting in Vienna in March 2001. Overall, the performances were good and most laboratories scored well. At that meeting a further expansion of the group's activities was also discussed to encompass the clinical evaluation of results obtained from autoantibody tests. A pilot scheme may be run as part of the 2001-2002 exercise, which would also continue to have both sera and image components. At this meeting it was agreed that Professor Manfred Renz from Karlsruhe, Germany, should join the organising committee.

ORGANISING COMMITTEE

Co-chairmen: Allan Wiik, Copenhagen, Denmark and Ruud Smeenk, Amsterdam, The Netherlands.

Members: Manfred Renz, Karlsruhe, Germany and Peter Charles, London, UK.

\section{Consensus study group on cytokines}

This study group has focused on the standardisation of cytokine measurements-tumour necrosis factor, interleukin 8 (IL8), IL10, and IL6. Serum samples were sent around and results were distributed among participating centres. However, during the past year the number of participating centres dropped. This may be attributed to the fact that many assays are commercial and that this group 
has neither the infrastructure nor ambition to assure a quality control system. Future activities of this group were discussed in Prague.

\section{Study group on synovitis}

The activities of the synovitis study group focus on the development of the synovial biopsy technique for the diagnostic armamentarium of rheumatologists. Now, training courses in arthroscopy are regularly organised by EULAR. A recently completed survey of arthroscopy in rheumatology identified 24 centres in 10 European countries that frequently use arthroscopic techniques. The participants of this study group collaborate in research on $(a)$ the need to establish acceptable guidelines for training European rheumatologists in arthroscopic techniques; $(b)$ issues relating to tissue selections and preparation; and (c) the methodology needed to quantify the immunohistochemical features of synovial inflammation. The process developed informally with biannual meetings, and a useful forum has evolved for discussing research protocols and data that incorporated synovial biopsy and tissue analysis.

ad. a. After considerable discussion, this task has been completed and a document submitted to ILAR for approval and distribution. The document, which will be published, identifies minimum requirements for accreditation of trainers and training centres, and outlines a basic curriculum for acquiring the necessary skills in arthroscopy. In addition, procedures for the assessment and accreditation of trainees are proposed.

$a d$. b. Collaborative research established that given the practical advantages the use of the closed needle biopsy is justified in many clinicopathological studies. ad. c. Close correlations were reported between quantitative and semiquantitative scoring methods. The various studies also provided support for further development and wider applications of digital image analysis. Standardisation of processes for quantifying the features of synovial analysis and inflammation, both macroscopically and microscopically, will be completed in the coming year. Other major interests of the group have been the evaluation of pathophysiological processes in the synovial tissue and the changes in these processes in patients receiving new targeted treatments.

This study group is coordinated by Professors PP Tak (Amsterdam) and B Bresnihan (Dublin).

For review see Bresnihan B et al. Synovial biopsy in arthritis research. Ann Rheum Dis 2000;59:506-10.

\section{Study group on biochemical markers for cartilage and bone metabolism}

The activities of this group came to an end because the coordinator discontinued his activities. This field is confronted with the fact that clearly effective markers are not available. This lessens the need for a study group, particularly when consensus and implementation issues are involved. In Prague, June 2001, a scientific symposium on biochemical markers was held, followed by discussions on the future of this study group.

A new study group on genomics and proteomics will be formed.

Leiden University Medical Centre, Department of Rheumatology, 2300 R C Leiden, The Netherlands
During the past years two new organisations have been created to support development in the field of paediatric rheumatology, the Paediatric Rheumatology European Society (PRES) and the Paediatric Rheumatology International Trials Organisation (PRINTO). Together with the EULAR Standing Committee on Paediatric Rheumatology, these organisations form a strong network for the promotion of research, education, and clinical development in paediatric rheumatology in Europe. An important task for the standing committee is to form a strong link between rheumatologists primarily caring for adults and those who primarily care for children in order to exchange knowledge, and in all aspects facilitate fruitful collaboration between the different organisations.

At the yearly meeting of the standing committee in Nice, June 2000, there was a consensus on the wish to arrange the yearly PRES meeting concurrently with the yearly EULAR congress to be held in Stockholm in June 2002. A similar wish was stated by the PRES general assembly held in Geneva, September 2000. The EULAR Executive Committee were supportive of this idea, and it has now been decided that PRES will have its yearly meeting integrated into the EULAR Congress in Stockholm. The programme is already being assembled, and there will be integrated sessions for adult and paediatric rheumatologists as well as sessions arranged primarily for paediatric rheumatologists by PRES. We hope this will be an excellent opportunity to meet, network, and exchange knowledge.

Successful clinical research has been initiated by PRINTO, supported by EU grants. Validation of the Child Health Assessment Questionnaire (CHAQ) and Child Health Questionnaire (CHQ) has been concluded in most
European countries and will soon be published in a supplement to Clinical and Experimental Rheumatology. The validated questionnaires form important parts of "the core set of outcome" for studies of juvenile idiopathic arthritis (JIA) proposed by a working group in PRINTO. A multicentre trial on parenteral methotrexate in medium versus higher doses in children with JIA has been successfully concluded using the abovementioned "core set of outcome". In April 2001 a consensus conference on core set of outcome measures for juvenile systemic erythematosus and juvenile dermatomyositis was held with representatives from 40 nations.

PRES has worked actively on educational issues. Paediatric rheumatology is now a UEMS subsection of the Confederation of European Specialists in Paediatrics and a syllabus and training programme have been approved by UEMS. Work is in progress on training records and accreditation of centres.

PRES held a successful scientific meeting in Geneva in September 2001, with 400 delegates, and the abstracts were published by the Annals of the Rheumatic Diseases (2001;60:suppl II). The next yearly meeting will be held in Utrecht, 27-30 September 2001. A special meeting for young investigators will be held in conjunction with the PRES meeting.

For further information see www.pres.org.uk, where you will also find links to EULAR and PRINTO, or www.eular.org, where you will find a link to PRES.

Chairman, Standing Committee on Paediatric Rheumatology

B A GÄRE

boel.andersson-gare@1tikpg.se 


\section{EULAR Standing Committee for Social Leagues activities in 2000}

\section{Chair's report}

The EULAR Standing Committee for Social Leagues has grown both in size and activity during the past few years, thanks to the active involvement of all the members. EULAR Social Leagues have a shared goal of improving quality of life and services for people with arthritis/ rheumatism. They are now more active than ever before, participating in the remarkable improvement of EULAR activities with an increasing partnership.

\section{Profile within EULAR meetings}

EULAR Social Leagues have an increasing profile within the EULAR meetings. After the meetings in Geneva in 1998 (three days joint programme for health professionals and social leagues) and Glasgow in 1999 (one day stand alone programme), the Social Leagues Programme Committee planned a three day programme for the first annual EULAR Congress in Nice, including one shared day with the health professionals. The programme was well received and attended. The same format was decided for the EULAR 2001 Congress in Prague, with an additional full joint session, on the theme "Communication and partnership", involving not only social leagues and health professionals but also rheumatologists. We are preparing more full joint sessions in the future.

In Nice, we paid particular attention to the question of access for people with disabilities, which is mandatory for the congresses. During the opening ceremony, one of the official speakers was a woman with arthritis; we hope similar participation will continue over the following EULAR Congresses.

\section{The European manifesto for the third millennium} This manifesto was announced during the opening ceremony of the congress in Prague. This initiative had been successfully launched during the congress in Nice. The manifesto was developed by the EULAR Standing Committee for Social Leagues, together with representatives from Arthritis and Rheumatism International and International Organisation of Youth with Rheumatism. It is aimed at determining what the society can do to improve life for people with arthritis/rheumatism. This declaration of the rights of people with arthritis/rheumatism establishes 10 "calls for action" for meeting the growing challenges presented by arthritis/rheumatism, which will form the basis of the social leagues programme during the annual EULAR Congresses, as from EULAR 2001 in Prague. The manifesto is now in the next stage of its development, which includes increasing administrative support and providing translation for each country.

\section{Stand alone conferences}

The EULAR Social Leagues also organise annual stand alone conferences-for example, the worldwide conferences of arthritis and rheumatism patient societies organised by the Social Leagues of EULAR in collaboration with Merck Sharp \& Dohme. After Amsterdam and Madrid, the third conference was held in Ljubljana on 14-15 October 2000. We had a very successful two day programme with the themes: "Developing your organisation" and "Disability politics and arthritis", with a convener for each theme (Barbro Allardt Ljunggren and Michael Bernardy). Sixty nine patient society representatives and 23 countries were represented. Most of the speakers and chairpersons were again people with arthritis/rheumatism.

We are planning the fourth worldwide conference "Arthritis patient on the move 2001", to be held early November 2001.

\section{Stene Prize}

EULAR Social Leagues award the Edgar Stene Prize to a person with arthritis/rheumatism for an essay on a topic chosen by the leagues. Historically, the prize has been awarded every four years. From 2001, it will be awarded every two years, during the annual congress; the EULAR Executive has increased the amount to 3000 Swiss Francs. In 2000, we had 39 entries (15 in 1999). The winner was Ms Frances Bell (UK) for her wonderful essay, "The long way to acceptance of my chronic disease".

\section{Other projects}

EULAR Social Leagues also have several other projects, including participation in the Bone and Joint Decade initiative (International Steering Committee and National Action Network activities); participation in the ILAR Congress in Edmunton; a booklet on social leagues, with input into the EULAR web site; training courses for social leagues and awards for educational projects, made possible with EULAR grants.

I would like to express heartfelt thanks to all the committee members, to Bruno Van Albada our past Chair, to Ms Sophie Edwards our secretary, to Fred and Elly Wyss and Eugenio Plozza at the executive secretariat, and to the executive committee members for their warm support.

\section{Perspectives}

In the future, EULAR Social Leagues will continue to grow in size and influence, and continue with collective campaign work through its manifesto and the Bone and Joint Decade initiative. We will examine our aims and our activities to ensure that we continue to meet the needs of EULAR, of our members, and of people with arthritis/ rheumatism.

CHU L'Archet,

L EULLER-ZIEGLER

Service de Rhumatologie, 62002 Nice, France 